Lieuwe D.J. Bos

l.d.bos@amc.uva.nl

@Acute_Pulmo_Med

Doing science

\title{
How to chair a poster discussion session
}

Poster discussion sessions are one of the most exciting and interactive sessions at which to present and hear about the latest research. Presenters can benefit from the best of two worlds: the central podium of a lecture and an in-depth discussion normally only encountered at the thematic poster sessions.

More than in other sessions, the chairs play an essential role in shaping the discussion and increasing the quality of the session. This article provides suggestions and practical tips for chairing a poster discussion session, taking into account the variation between sessions and presenters. The aim is to provide a guideline that can be followed by chairs while maintaining room for their own interpretation and style. The most important points are summarised in figure 1 .

\section{Preparation}

Preparation is pivotal for chairing a poster discussion session. This is not a plenary lecture where you can sit back and let the speakers do their magic. Nor is it a thematic poster session involving a one-to-one discussion with presenters. Structuring a large-scale discussion requires preparation and if the chair is not going to do this, the chair is probably going to be the reason for a mediocre session. What are the steps required in the weeks before the session?
1) Read all the abstracts. Write questions down for each presenter that could be used to start a discussion if no input comes from the audience. This is frequently the case if the chair does not break the ice by asking a question.

2) Group the abstracts into topics. It is easier to discuss a topic when multiple presentations on a similar subject are grouped together. This may not be the case by default and you may need to adjust the order of presentations when this is the case

3) Prepare discussion points for each topic. Besides questions for individual presenters, it is recommended to prepare discussion points for each topic identified under point two. One trick is to take positions (in favour or against) a central hypothesis and to ask the presenters to discuss their point of view.

4) Contact your co-chair. It is essential to discuss the format beforehand and it's great to share the work between the chairs. The European Respiratory Society encourages partnering an early career member chair with a more senior chair. In general, the younger chair will need to do more preparation than the senior. The advantages from this approach work both ways: the early career member will benefit from the experience of the senior, while the senior will gain from the preparation undertaken by the early career member.
Cite as: Bos LDJ. How to chair a poster discussion session. Breathe 2019; 15: 131-134

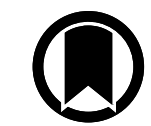

CrossMark

C ERS 2019 


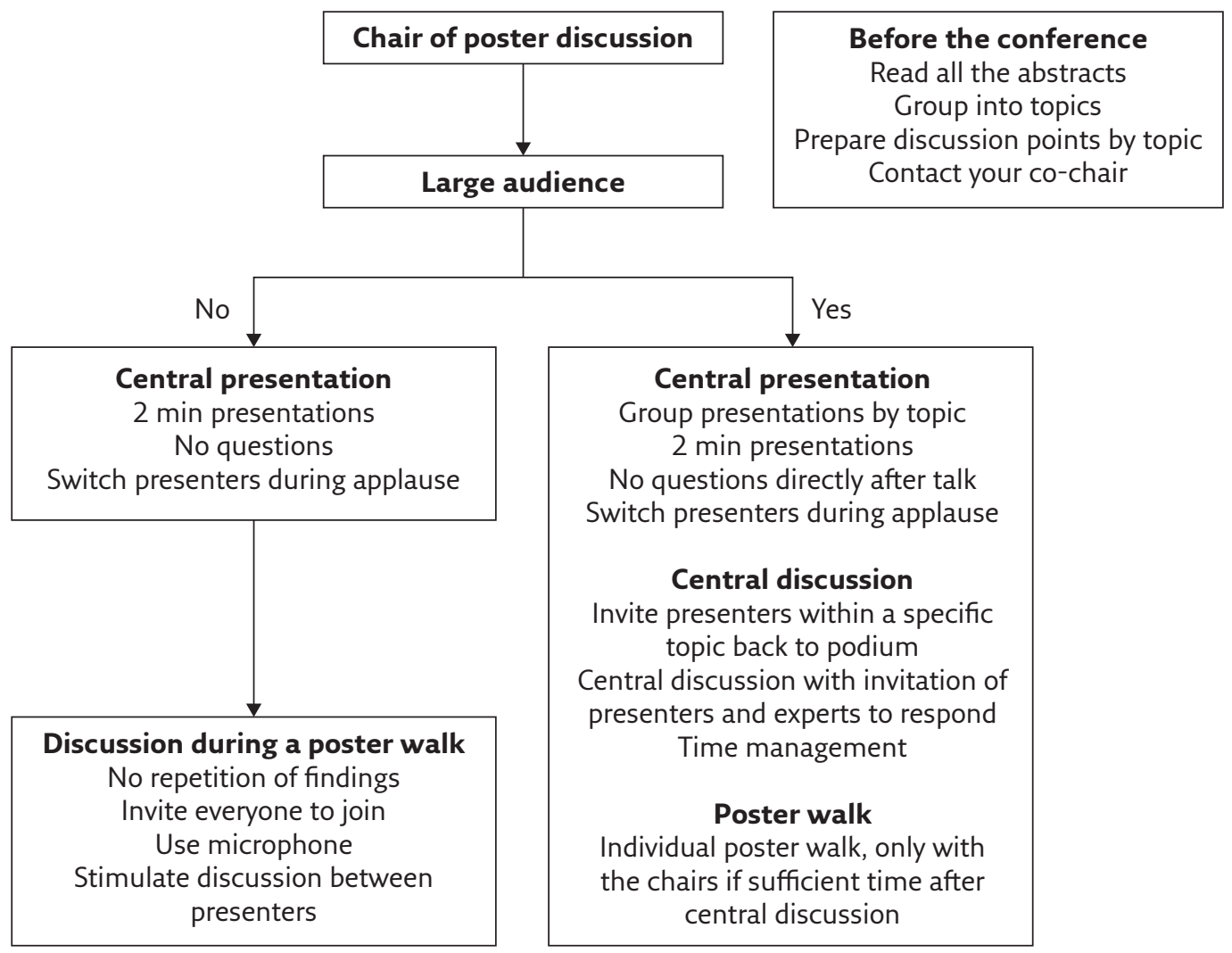

Figure 1 Summary of relevant points for chairs of a poster discussion session.

5) Use your network. Any invited chair is already an expert in the field, otherwise you would not have been asked to chair the poster discussion session, but there may be specific points that your colleagues know more about. If they are also attending the conference you could urge them to attend the session and "use" their expertise about certain topics to guide the discussion.

\section{The big day}

The day has come to chair the poster discussion session. Fortunately, you are well prepared: you know the abstracts, have grouped the presentations into topics and have questions to hand. Now, you should be in the room 10-15 min before the session starts to do a final walkthrough with your co-chair. Also, you could encourage attendees to take a seat in the front rows. You can also introduce yourself to speakers and early bird attendees to break the ice and increase the likelihood that they will contribute to the discussion. There are two parts to a poster discussion: the authors present their work in the form of a 2-min pitch followed by a discussion of the presented topics. As the room fills, there is an important decision to be made about the format based on the number of attendees, as outlined in the following two sections.

\section{A small audience in the room}

With a small group of attendees in the room it is possible to do a poster walk together and to have a group discussion with everyone present.

\section{Pitches}

This allows for en bloc presentation of the pitches and a separate poster walk. The following method is suggested: use a stopwatch to give each presenter a maximum of 2 min to present their work. This format was communicated with them before the conference and it is essential to keep to time. Furthermore, it is an essential skill for young researchers to present succinctly. Do not allow a presenter to keep talking beyond $2 \mathrm{~min}$, to allow as much time for discussion as possible. Do not feel bad about interrupting; it is one of your tasks during the session and it will only improve the quality of the session. I like to switch presenters during the applause so as to not lose time, but this should be communicated to the speakers at the start of the session.

\section{Poster walk}

After all the pitches have been made, it's time for the poster walk. Invite everyone to walk with you past 
Table 1 Tips on how to run a poster discussion

\begin{tabular}{|c|c|}
\hline Aim & Method \\
\hline Discussion of interest to everyone & $\begin{array}{l}\text { Do not talk about a single result but rather about a larger topic that is of interest to } \\
\text { the whole audience. }\end{array}$ \\
\hline Start a discussion & $\begin{array}{l}\text { Prepare a list of discussion items and take a stand (which might be controversial) to } \\
\text { allow the audience to take another position. }\end{array}$ \\
\hline Discussion between the audience & $\begin{array}{l}\text { Do not kill discussions between the audience because you want to use your prepared } \\
\text { questions. The prepared questions are a backup. }\end{array}$ \\
\hline Elevate the room, not the chair & $\begin{array}{l}\text { Keep "smart" remarks to yourself and try to give space for the audience to come to } \\
\text { these conclusions. }\end{array}$ \\
\hline Increase the quality of the discussion & Invite experts in the field who are present in the room to contribute. \\
\hline Involve the introverts & $\begin{array}{l}\text { Reach out to specific people and ask them a direct question while handing the } \\
\text { microphone over. }\end{array}$ \\
\hline Break the tension & $\begin{array}{l}\text { Introduce yourself before the session starts to the people who are present. If you } \\
\text { can, make some jokes in between presentations. }\end{array}$ \\
\hline Stay on time and focus the discussion & Interrupt anyone who is monopolising the discussion or who is taking too much time. \\
\hline
\end{tabular}

the posters. The authors should not present their work again, you can jump straight into questions and discussion. There is a wireless microphone that can be used for sound augmentation. This also facilitates the organisation of the discussion because only one person can speak at a time. Furthermore, you can actively engage other presenters or experts in the field by asking them a question and reaching the microphone out to them. Even the most introverted presenter can be convinced to share his or her opinion this way. When the discussion dries out, one can proceed to the next poster to discuss another topic. Table 1 provides a list with tips on how to run a discussion. Importantly, you don't have to hurry to cover all posters. If you can engage all speakers and attendees at an early point in time, it is perfectly fine not to walk past all the posters. It might be good make the presenters aware that they can go to their posters in between if there is someone there to ask a question. The group should not have any problems with the sound of other discussions due to the use of a microphone. The presenters should not be standing around at their posters when there is nobody there but should join the group discussion.

\section{A large audience}

With a large group of attendees, it is much more difficult to do a poster walk with the whole group. Also, the murmurs from the discussions at each poster might be louder than the sound of the microphone. Therefore, a different approach is proposed for larger groups.

\section{Pitches}

All rules for pitches are the same as discussed above, the only proposed difference is to group the pitches together based on topics. Remember the 2-min time limit. After a topic has been covered by three to six pitches, a central discussion can be held with the presenters within that topic.

\section{Central discussion}

Because the group is too large for a poster walk it is recommended to have a central discussion directly after the discussion of a single topic. First, invite all speakers to the front of the room, in front a microphone. If there is no input from the room, don't worry; you have prepared several points of discussion that you bring to the floor. You can also discuss (seemingly) conflicting results between the studies. A great trick to improve the quality of the discussion is to identify key opinion leaders in the room and ask their take on the subject at hand. This frequently leads to the unsolicited opinion of another "giant" in the field and all of a sudden there is a discussion between the presenters and these experts. Table 1 provides a list of other tips and tricks.

With regards to time management, you can use the same time for discussion as the time that was allocated for the pitches within this theme and still stay within the limits of time. Of course, if the pitches took more time (How could that have happened? You stopped them after 2 min, right?) you also need to restrict the time spent on the discussion.

\section{Poster walk}

A poster walk can be initiated if there is time left after all pitches and subsequent central discussions. This cannot be done the same way as with a smaller group and the chairs should encourage the presenters to take their place at their posters to allow for decentralised discussions. The role for the chairs in this part of the session is limited. 


\section{The end of the session}

When there are a couple of minutes left it is advised to take a few minutes to thank all the presenters and attendees for their time and contributions, and to highlight another session on the programme that might be of interest to the audience. Please do not forget to fill in the papers on the number of attendees and the quality of the presentations and discussion. It's time for the next session, run!

Affiliations

\section{Lieuwe D.J. Bos}

Intensive Care, Amsterdam UMC, Location AMC, Amsterdam, The Netherlands.

\section{Conflict of interest}

L.D.J. Bos reports grants from the Dutch lung foundation (Young investigator grant), the Dutch lung foundation (Public-Private Partnership grant) and the ERS (short-term fellowship), and personal fees from Bayer (for consultancy), outside the submitted work. 